\title{
Adli Yaş Tahmini Yapılan Olguların Değerlendirilmesi: Retrospektif Bir Çalışma
}

\author{
Evaluation of Forensic Age Estimation Cases: A Retrospective Study
}

Mustafa Talip ŞENER, Şaban POLAT

Atatürk Üniversitesi Tip Fakültesi, Adli Tip ABD, Erzurum

Geliş tarihi: 24.12.2019, Kabul tarihi: 24.02.2020, DOI: 10.17517/ksutfd.664337

\begin{abstract}
Özet
Amaç: Günümüzde adli yaş tahmini, doğum tarihleri güvenilir bir şekilde belgelenemeyen bireyler için önemini korumaktadır. Adli yaş tahmin nedenleri, ülkelere ve bölgelere göre farklllık gösterebilir. Adli yaşın tahmin edilmesinin isteme nedenleri ülkelere ve bölgelere göre farklılıklar gösterebilmektedir. Bu çalışmada bölgemizde, adli mercilerce gönderilerek adli yaş tahmini yapılması istenen olgulara ait demografik değişkenleri ve yaş tespit nedenlerini belirlemeyi amaçladık.

Gereç ve Yöntemler: Bu çalı̧̧mada 01.03.2016 ile 01.03.2019 tarihleri arasında adli makamlar tarafından adli yaş tahmini yapılması istemi ile gönderilen olgular retrospektif olarak incelendi. Bu çalışmada 216 olgunun demografik verileri ile fiziksel gelişim bulguları ve direkt grafileri incelendi.

Bulgular: Olguların \%63,9’u (n=138) kadın idi. Kimlik kayıtlarına göre ortalama yaş 19,9 olup olguların \%77,8'i $(\mathrm{n}=168) \leq 22$ yaşında bulundu. Olguların \%81'inin ( $\mathrm{n}=175)$ doğumlarının evde gerçekleștiği öğrenildi. Olguların \%7,9'una (n=17) ceza hukuku bakımından yaş tahmini yapılması istenmişti. Olguların \%83,2'sinin (n=190) $4 \leq$ kardeşi vardı. \%10,2'sinin (n=22) okur yazar olmadığı ve \%59,8'inin ( $\mathrm{n}=47)$ ilk-ortaokul eğitim seviyesinde olduğu bulundu.

Sonuç: Bulgularımıza göre; adli yaş tahmini olgularının önemli bir kısmı, 20 yaşın altındaki düşük eğitimli kalabalık aile çocukları idi. Olguların büyük kısmının doğum yerlerinin kırsal bölgeler olup doğumlarının sağlık kuruluşu dışında gerçekleşmiş olduğu görüldü.
\end{abstract}

Anahtar Kelimeler: Adli yaş tahmini, kimlik yaşı, kemik yaşı

\section{Abstract}

Objective: Today, forensic age estimation is essential for individuals whose birth dates cannot be reliably documented. The reasons for forensic age estimation may vary by country and region. The presence of different populations may make the selection of reference atlas challenging to assess. In this study, we aimed to determine the demographic variables and causes of forensic age estimation cases sent by judicial authorities in our region.

Material and Methods: In this study, cases that were sent by the judicial authorities with the request of forensic age estimation between 01.03.20116 and 01.03.2019 were examined retrospectively. In this study, cases of 216 were examined demographic data, physical development findings and direct radiography.

Results: $63.9 \%(\mathrm{n}=138)$ of the cases were female. According to the identity records, the mean age was 19.9 , and $77.8 \%(\mathrm{n}=$ $168)$ of the cases was $\leq 22$ years old. $81 \%(n=175)$ of the cases were born at home. $7.9 \%$ of the cases $(n=17)$ were asked to determine the forensic age in terms of criminal law. $83.2 \%(n=190)$ of the cases had $4 \leq$ siblings. It was found that $10.2 \%(n=$ 22) were illiterate and $59.8 \%(n=47)$ were educated at primary and secondary level.

Conclusion: According to the findings, a significant portion of the forensic age estimation cases are low-educated crowded family children under 20 years of age. Most of the cases were born in rural areas, and their births were outside the health institution.

Keywords: Forensic age estimation, identity age, bone age

Yazışma Adresi: Mustafa Talip ŞENER Atatürk Üniversitesi Tip Fakültesi, Adli Tip ABD, Erzurum Tlf: +90 5057856861 E-mail: mustafatalipsener@gmail.com

ORCID No (Sırasıyla): 0000-0002-1295-7710, 0000-0002-9721-3090 


\section{GİRIŞ}

Yaş, insanların tıbbi kimliğini oluşturan fiziksel özelliklerinden biridir.Takvim yaşı, bireyin doğum gününden başlayarak hesaplanan güne dek yaşadığı yıl, ay ve gün olarak belirlenmiş süredir. Kemik yaşı ise kemiklerin boyut, şekil ve mineralizasyonunun olgunlaşmaya yakınlık derecesi anlamında kullanılan kronolojik yaş olarak ifade edilmektedir $(1,2)$.

Doğum tarihlerinin güvenilir bir şekilde belgelenmediği bireylerde adli yaş tahminlerine ihtiyaç duyulmaktadır. Günümüzde adli yaş tahmini, adli tıp uygulamalarında özellikle medeni hukuk veya ceza hukuku bakımından önemini koruyan değerlendirme alanından biridir $(3,4)$. Adli yaşın tahmin edilmesinin isteme nedenleri ülkelere ve bölgelere göre farklılıklar gösterebilmektedir (5). Ülkemizde özellikle kırsal kesimde çocukların nüfusa geç kaydedilmesidir. Nüfus kayıt bilgilerinin doğruluğu şüpheli olan kişilerin varlığg nedeni ile gerek yargıya intikal eden olaylarda ceza kanunu bakımından, gerekse okula başlama, işe girme, evlenme ve askere alınma gibi durumlarda yaşayan bireylerde adli yaş tahmini istenmektedir (6). Bu çalışmada, adli mercilerce Atatürk Üniversitesi Tıp Fakültesi Adli Tıp Anabilim Dalı’na adli mercilerce gönderilerek, adli yaş tahmini yapılması istenen olguların demografik değişkenleri, yaş tahmin nedenleri gibi verilerini inceleyerek, adli yaş tahmini yapılan olguların bölgemize ait verilerinin belirlenmesini ve adli yaş tahmin sonuçlarının değerlendirilmesini amaçladık.

\section{GEREÇ ve YÖNTEMLER}

\section{Olguların seçimi}

Bu çalışmada 01.03.2016 ile 01.03.2019 tarihleri arasında Atatürk Üniversitesi Tıp Fakültesi Adli Tıp Anabilim Dalı’na adli makamlar tarafından adli yaş tahmini yapılması istemi ile gönderilen olgular tarandı ve çalışma kapsamda 216 olgu çalışmaya dahil edildi. Olguların adli yaş belirlenme nedenleri, kimlik yaşı, cinsiyet, doğum yeri, doğumun gerçekleştiği yer, eğitim durumu, kardeş sayısı gibi demografik verileri retrospektif olarak değerlendirildi.

\section{Olguların adli yaşlarının tahmini}

Olguların adli yaş tahminlerinde kilo, boy, diş gelişimi ve sayısı, Tanner-Marshall evrelemesi gibi fiziksel gelişim bulguları ile yaşlarına uygun çekilen direkt grafileri radyoloji uzman görüşü ile birlikte değerlendirildi.

Adli yaş tahmininde direkt grafiler öncelikle Gök atlası olmak üzere (Adli Tipta Yaş Tayini: Prof. Dr. Şemsi Gök, Dr. Nihat Erölçer, Prof. Dr. Cahit Özen), Greulich ve Pyle (G-P) atlas1, Tanner-Whitehouse (T-W) skorlaması, V. Gilsanz-O. Ratib atlaslarına göre eşleştirildi (7).

Radyolojik olarak olguların adli yaş tahmininde; 0 -22 yaş aralığında el-el bileği, lateral dirsek, humerus üst epifiz ve diafizi gösteren omuz (AP), ön-arka ve lateral pelvis grafileri, 22-50 yaş aralığında yan sternum, PA akciğer, ön-arka ve lateral pelvis grafileri çekilerek değerlendirildi.

\section{İstatistiksel analiz}

Verilerin analizi için SPSS Windows 20.0 software programı kullanıldı. Verilerin yüzdelik, ortalama ve standart sapma değerleri hesaplandı. Gruplar arası karşılaştırmalar Ki-kare testi ile analiz edildi. $\mathrm{P}<0,05$ değeri istatistiksel olarak anlamlı kabul edildi.

Çalışma için Etik Kurul onayı alındı (Karar no: 26.09.2019/08).

\section{BULGULAR}

Olguların \%36,1'i (n=78) erkek, \%63,9’u (n=138) kadın idi. Olguların kimliklerinde kayıtlı olan yaş ortalaması 19,9 (sd: $\pm 11,7$; min: 10- maks: 84 ) olup kimlik yaşlarına göre $\% 77,8^{\prime}$ inin $(n=168) \leq 22$ yaş, \%22,2'sinin ise $(n=48) 22$ yaştan büyük olduğu belirlendi.

Olguların eğitim düzeyleri incelendiğinde; \%10,2'sinin $(n=22)$ okur-yazar olmadığı, \%21,8'inin $(n=47)$ ilkokul, \%38'inin $(n=82)$ ortaokul, \%22,2'sinin $(n=48)$ lise ve $\% 7,8$ 'inin $(\mathrm{n}=17)$ üniversite mezunu olduğu belirlendi. Olguların \%12,1'inin $(n=26) \leq 3, \% 83,2$ 'sinin $(n=190) 4 \leq$ kardeşinin olduğu öğrenildi.

Olguların adli yaş belirleme nedenleri sırasıyla, evlilik $(n=54)$, iş başvurusu yapma $(n=32)$, ceza hukuku nedeni ile ( $\mathrm{n}=17)$, kardeşi ile ikiz olup olmadığı $(\mathrm{n}=13)$, emeklilik $(n=11)$, eğitim $(n=8)$, askerlik $(n=7)$, sürücü ehliyeti alma $(n=1)$ ve hastane işlemleri $(n=1)$ olduğu, olgulardan 72 'sinin ise adli yaş belirleme nedenini belirtmediği saptandı. Cinsiyet ve yaş gruplarına göre olguların geliş nedenleri Tablo 1'de gösterildi.

Olguların \%67,6'sının ( $n=146)$ doğum yerinin ilçe-köy, \%32,4'nün ( $n=70)$ il merkezleri olduğu, olguların doğumlarının \%81'inin ( $n=175)$ evde, \%16,2'sinin $(n=35)$ sağlık kuruluşunda gerçekleştiği, \%2,8’i (n=6) ise doğumunun nerede olduğunun bilinmediği belirlendi.

Olguların \%13’ü $(n=28)$ kimlik yaşlarının doğru kayıt edildiği, \%87'si ise $(n=188)$ hatalı kayıt edildiği saptandı. Olgulardan doğumu evde olanların \%89,7’si ( $n=157)$, sağlık kuruluşunda olanlardan \%80'i (n=28) nüfus kayıtlarının doğru olmadığı belirlendi. Kimlik yaşının nüfusa hatalı kayıt edildiğini belirten olgulardan \%87,8'i $(n=165)$ kendi bildiği yaşın kimlik yaşından küçük, \%12,2'si ise $(n=23)$ büyük olduğunu iddia etmişlerdi. Kimlikteki yaşlarının doğru kayıt edildiğini belirten olgular, kimlikteki yaşının hatalı kayıt edildiğini belirten olgulardan küçüktü ( $\mathrm{p}=0,027)$. Ceza hukuku nedeni ile adli yaş belirlenmesi istenen olguların \%64,7'si ( $n=11)$ doğumlarının evde olduğunu söylemişlerdir. Doğumları evde olan olguların daha çok ceza hukuku yönü ile adli yaşlarının belirlenmesi istenmiştir ( $\mathrm{p}=0,026)$ (Tablo 2). 


\begin{tabular}{|c|c|c|c|c|c|c|c|c|c|c|}
\hline \multirow[t]{2}{*}{ Müracaat nedenleri } & \multicolumn{2}{|c|}{ Cinsiyet } & \multicolumn{7}{|c|}{ Yaş Grupları } & \multirow[t]{2}{*}{ Toplam } \\
\hline & Erkek & Kadın & 0-10 & $11-20$ & 21-30 & $31-40$ & 41-50 & $51-60$ & $61 \leq$ & \\
\hline $\begin{array}{l}\text { Ceza hukuku } \\
\text { kapsamında }\end{array}$ & 7 & 10 & - & 16 & 1 & - & - & - & - & 17 \\
\hline Evlilik & 3 & 51 & - & 52 & 1 & 1 & - & - & - & 54 \\
\hline İş başvurusu & 15 & 17 & - & 26 & 3 & 3 & - & - & - & 32 \\
\hline İkiz olup olmadığı & 5 & 8 & - & 11 & 2 & - & - & - & - & 13 \\
\hline Emeklilik & 7 & 4 & - & - & - & - & 3 & 2 & 6 & 11 \\
\hline Eğitim & 1 & 7 & - & 7 & 1 & - & - & - & - & 8 \\
\hline Askerlik & 7 & - & - & 5 & 2 & - & - & - & - & 7 \\
\hline Ehliyet & - & 1 & - & 1 & - & - & - & - & - & 1 \\
\hline Hastane işlemleri & - & 1 & - & 1 & - & - & - & - & - & 1 \\
\hline $\begin{array}{l}\text { Neden } \\
\text { bildirmeyenler }\end{array}$ & 33 & 39 & 2 & 53 & 8 & 4 & 3 & 1 & 1 & 72 \\
\hline Toplam & 78 & 138 & 2 & 172 & 18 & 8 & 6 & 3 & 7 & 216 \\
\hline
\end{tabular}

Tablo 2. Olguların yaş ile ilgili nüfus kayıt bilgileri ile demografik verilerinin karşılaştırılması.

\begin{tabular}{|c|c|c|c|c|c|c|}
\hline & & \multicolumn{4}{|c|}{ Nüfus kaydının doğruluğu* } & \multirow[t]{3}{*}{ P değer } \\
\hline & & \multicolumn{2}{|c|}{ Hayır } & \multicolumn{2}{|l|}{ Evet } & \\
\hline & & $\mathrm{n}$ & $\%$ & $\mathrm{n}$ & $\%$ & \\
\hline \multirow[t]{2}{*}{ Cinsiyet } & Erkek & 69 & 88,5 & 9 & 11,5 & \multirow[t]{2}{*}{$>0.05$} \\
\hline & Kadin & 119 & 86,2 & 19 & 13,8 & \\
\hline Yaş & Ortalama $( \pm$ sd) & 23,2 & 13,1 & 17,5 & 9,3 & 0,027 \\
\hline \multirow[t]{2}{*}{ Doğum yeri } & İl merkezi & 59 & 84,3 & 11 & 15,7 & \multirow[t]{2}{*}{$>0.05$} \\
\hline & İlçe & 129 & 88,4 & 17 & 11,6 & \\
\hline \multirow[t]{2}{*}{ Doğumu } & Hastanede & 28 & 80 & 7 & 20 & \multirow[t]{2}{*}{$>0.05$} \\
\hline & Evde & 157 & 89,7 & 18 & 10,3 & \\
\hline \multirow[t]{5}{*}{ Eğitim } & Okuryazar değil & 20 & 90,9 & 2 & 9,1 & \multirow[t]{5}{*}{$>0.05$} \\
\hline & İlkokul & 40 & 85,1 & 7 & 14,9 & \\
\hline & Ortaokul & 72 & 87,8 & 10 & 12,2 & \\
\hline & Lise & 39 & 81,2 & 9 & 18,8 & \\
\hline & Üniversite & 17 & 100 & 0 & 0 & \\
\hline \multirow[t]{2}{*}{ Yaş belirleme nedeni } & Ceza hukuku nedeni ile & 8 & 47,1 & 9 & 52,9 & \multirow[t]{2}{*}{$<0.001$} \\
\hline & Yaş düzeltmesi amacıyla & 180 & 90,5 & 19 & 9,5 & \\
\hline
\end{tabular}




\section{Tablo 3. Olguların belirttiği yaş ile adli-tıbbi değerlendirme bulgularının karşılaştırılması.}

\begin{tabular}{|l|c|c|}
\hline & \multicolumn{2}{|c|}{$\begin{array}{l}\text { Adli-tıbbi değerlendirme ile belirtilen yaş arasında } \\
\text { uyum }\end{array}$} \\
\hline Uyum durumu & $\mathrm{n}$ & $\%$ \\
\hline Tam uyumlu & 97 & 44,9 \\
\hline 1 yll fark & 82 & 38 \\
\hline 2 yll fark & 23 & 10,6 \\
\hline 3 yll fark & 8 & 3,7 \\
\hline 4 yll fark & 4 & 1,9 \\
\hline 5 yll fark & 2 & 0,9 \\
\hline
\end{tabular}

\section{TARTIȘMA}

Adli tıp uygulamalarında yaşayan bireylerde evlilik, askere alınma, okula başlama, memuriyete girme, emekli olma, sürücü belgesi alma, Türk Ceza Kanunda da yer alan cezai ve hukuki sorumluluğun belirlenmesi gibi nedenlerle adli yaşın belirlenmesi istenmektedir (8). Çalışmamızda da olguların başvuru nedenleri incelendiğinde cezai ve hukuki sorumluluk kapsamında adli yaş tahmini değerlendirilmesinin daha az olduğu, sırasıyla erkeklerde iş başvurusu, askerlik ve emeklilik işlemleri, kadınlarda ise evlilik ve iş başvurusu olduğu görüldü. Olguların kimlik yaşları ile adli yaş belirlenme nedenleri karşıllaştırıldığında; olguların hukuki, sosyal ve ekonomik alanlarda önemli olan 20 yaş altı grupta yoğunlaştığı ve büyük çoğunluğunun kadın olduğu tespit edildi. Türkiye'de yapılan benzer çalışmalarda da adli yaş tahmini yapılan olguların büyük kısmını kadınların oluşturduğu ve evlilik, askere alınma, okula başlama, memuriyete girme, emekli olma, sürücü belgesi alma gibi nedenlerle adli yaş tahmininin değerlendirildiği görülmektedir (9-11).Bulgularımıza göre genel olarak olguların yaş tahmin nedenlerinin daha çok sosyal ve ekonomik kökenli olduğu söylenebilir.

Türkiye Nüfus Sağlık Araştırması (TNSA) 2013 verilerine göre çocukların \%1’inin nüfus kaydının okula kayıt, evlilik, askerlik gibi yasal zorunluluğun olduğu dönemlerde yapıldığı, özelikle kırsal kesimde ve doğu bölgelerinde nüfus kayıtlarının tam olmadığı bildirilmektedir. TNSA 1998 sonrasında doğan çocukların verilerinin incelendiği araştırmada; bu dönemde doğan çocukların \%16’sının nüfus cüzdanının olmadığı, bu oranın \%17,2 ile kız çocuklarında daha fazla olduğu ve bu çocukların daha çok ülkemizin doğusunda ve kırsal bölgelerde yaşadığı belirtilmektedir (12). Çalışmamızda da yaş tahmini amacıyla adli değerlendirmesi yapılan olguların doğum yerleri, eğitim düzeyleri ve kardeş sayıları dikkate alındığında adli yaş tahmini yapılan popülasyonun, daha çok kırsal bölgelerde, eğitim düzeyi düşük ve kalabalık ailelerde yaşayan kişilerden oluştuğu görülmektedir.

TNSA 2008 verilerine göre ülkemizde doğumların \%90'1, Sağlık Bakanlığı Sağlık İstatistikleri Yıllığ 2017 Haber Bülteni verilerine göre ise doğumların \%98'i sağlık kuruluşlarında olmaktadır (13). 25.4.2006 kabul tarihli ve 5490 numaralı Nüfus Hizmetleri Kanununa göre, Türkiyede doğum kayıt- ları İçişleri Bakanlığı’na bağlı Nüfus ve Vatandaşlık Genel Müdürlüğü tarafından yürütülen Mernis projesi kapsamında tutulmaktadır. Buna göre sağ olarak dünyaya gelen her çocuğun, doğumdan itibaren Türkiye'de otuz gün içinde nüfus müdürlügüne, yurt dışında ise altmış gün içinde dış temsilciliğe bildirilmesi zorunludur. Aynı zamanda sağlık kuruluşları ve sağlık kuruluşları dışında sağlık personeli nezaretinde gerçekleşen doğumların, ilgili sağlı birimince beş iş günü içinde nüfus müdürlüğüne bildirilme zorunluluğu da bulunmaktadır. Sağlık personelinin takibi dışında doğan çocukların doğum bildirimi nüfus müdürlüklerine sözlü beyanla yapılmaktadır. Mülki idare amirinin emri ile aile hekimlerince her sözlü beyanın doğruluğunun araştırılması zorunludur. Geçmiş dönemlerde kanunda belirtilen süre içerisinde nüfusa kaydı bildirilmeyen doğumlar için kayıt cezası alınmakta idi. Ancak bu durum, ailelerin para cezasını ödememek için bebeklerinin yaşını daha küçük olarak bildirmelerine ve nüfus kayıtlarının yanlış tutulmasına sebebiyet veren nedenler arasında olduğu için genelge ile bu para cezası kaldırılmıştır (14). Bununla birlikte mahkemece yaş değişikliğine karar verilebilmesi için sıkı şartlar da öngörülmüştür. Kişinin resmi veya özel bir sağlık kuruluşunda doğmuş ve buna ilişkin düzenlenen bir doğum tutanağına istinaden nüfusa kaydedilmiş ise bu tutanağın esas alınması, yaşını büyütmek isteyenlerin beyan edilen yaşta bir kardeşin olmaması, yaşını küçültmek isteyenlerin nüfusa yazımdan önceki tarihte doğduğunu iddia etmemesi gibi şartlar bulunmaktadır (15). Nüfus kayıtlarının düzenli tutulması yönünde yasal düzenlemeler bulunmakla birlikte; çalışmamızda doğumları sağlık kuruluşunda olduğunu, aynı zamanda nüfus kayıtlarının hatalı olduğunu belirten olguların da olduğu görülmüştür. Adli yaş tahmini yapılan olguların \%81 gibi büyük kısmını doğumları sağlık kuruluşu dişında gerçekleşen olgular oluşturmaktadır. Dolayısıyla bu olguların doğumlarının sağlık kuruluşunda olmaması ve nüfus kayıtlarının beyana dayalı olması nedeniyle nüfus kayıtlarının yanlış tutulduğuna yönelik iddialarının olması ve daha çok doğumları evde olduğunu belirten olguların adli yaş tahmini için gönderilmesi beklenen bir durumdur. Ancak, çalışmamızda olduğu gibi doğumlarının hastanede olduğunu, nüfus kayitlarının doğru olduğunu 
belirten olgularda, özellikle ceza hukuku nedeni ile adli makamlar tarafından adli yaşlarının belirlenmesi istenmektedir. Yaş belirlemesinde şüphe durumunda mahkemeler öncelikli olarak doğum kayıtlarını esas almaktadır. Ancak doğumları sağlık kuruluşunda olan olguların da adli yaşlarının belirlenmek için gönderilmiş olması, olguların sağlık kuruluşunda doğum kayıtları ile ilgili arşiv kayıtlarının düzenli tutulmadığını düşündürdüğü gibi adli makamların doğum kayıtlarını yeterince araştırmadan doğrudan rapor istemeleri de bu durumun nedenlerinden biri olabilir. Yasal düzenlemeler göz önüne alınarak, sağlık kuruluşlarında doğum kayıtlarının düzenli olarak tutulmasının ve arşivlenmesinin önemli olduğu ortaya çıkarmaktadır.

Adli yaş tahmin bulguları\%44,9 ( $\mathrm{n}=97)$ olguda belirtilen yaş ile uyumlu, \%38 ( $n=82)$ olguda ise 1 yıl farklı bulundu. Adli-tıbbi değerlendirme bulgularının, olguların belirttiği yaşı ile uyum durumu Tablo 3'de gösterilmiştir.

Yaşayan bireylerde adli yaş tahmini adli tıp uzmanı, radyoloji uzmanı, diş hekimi gibi uzmanların katılımı ile multidisipliner bir yaklaşımla yapılmaktadır. Yöntem olarak bireyin gelişimini etkileyen fizyolojik ve patolojik faktörler, boy, ağırlık, diş gelişimi, puberte belirtileri, ruhsal ve mental gelişim gibi fiziksel bulgular ile radyolojik olarak kemiklerin epifiz ve metafiz arası ossifikasyon gelişimi ile kemiklerin fizyolojik kalsifikasyon tamamlanma zamanları incelenmektedir $(16,17)$.Cinsiyet, 1rk, sosyoekonomik durum, obezite, diyabet, travma, hipotiroidi, büyüme hormonu eksikliği, çölyak hastalığı, ülseratif kolit, nefrotik sendrom, guatr, hiperkalsemi, fenilketonüri, Down sendromu, Turner sendromu, Angelman sendromu gibi metabolik, hormonal ve konjenital hastalıklar kemiklerin erken veya geç gelişmesine neden olabilmektedir $(11,18)$. Radyolojik incelemede karşılaştırma amacıyla başlıca Greulich ve Pyle (G-P) atlası, Tanner-Whitehouse (T-W) skorlaması, V. Gilsanz-O. Ratib atlası gibi batı toplumlarının standartlarına göre hazırlanmış atlaslar kullanılmaktadır (7). Ceza hukuku açısından önemli olan 12, 15, 18 gibi yaşlar için ayırt ediciliği yüksek olan MR gibi ileri incelemelere de ihtiyaç duyulabilir (19). Radyolojik olarak kemiklerin epifiz hatlarının kapanma derecelerine göre 22 yaşa kadar olan olgularda her yaş için yaklaşık bir tespit yapilabilmekte, puberte sonrası ve ileri yaşlarda ise kesin yaş tayini güçleşmekte, kemik yaşları daha geniş aralıklarda tahmin edilmektedir (3). Adli yaş tahmini değerlendirmesi multidisipliner bir alan olması, değerlendirmeyi yapan uzmanların değerlendirilecek unsurlar ile popülasyona özgü kemik gelişim farklılıkları konusunda farklı bilgi ve beceriye sahip olması, radyolojik olarak karşılaştırma atlaslarında belli standartlar olmaması gibi durumlar adli yaş tahminini zorlaştırabilir. Adli-tıbbi değerlendirmeye göre çalışmamızda olguların yaklaşık \%45'inin belirttiği yaşı ile tam uyumlu bulgu elde edilmiştir. Farklı toplumlarda yapılan çalışmalarda genel olarak kemik yaşın kronolojik yaşa göre yaklaşık olarak bir yıldan fazla farklılık gösterdiği, özellikle 22 yaş altında kemik yaşının kronolojik yaşa göre 2 yıllık standart deviasyona kadar farklılık göstermesi normal sınırlar içinde kabul edil- mektedir (17). Adli yaş tahminini etkileyen birçok faktör bulunmakla birlikte; çeşitli hukuki kazanç elde etme amacı ile bireyler içinde bulundukları yaşlarını olduğundan küçük ya da büyük ifade edebilirler (20). Çalışmamızda da kimlik yaşının nüfusa hatalı kayıt edildiğini belirten olgulardan \%87,8'i kendi bildiği yaşın kimlik yaşından küçük olduğunu belirtmiştir. Adli-tıbbi değerlendirme ile Tablo 3'de de gösterildiği gibi adli yaş tahmin bulguları,olguların belirttikleri yaşları ile büyük oranda benzer bulunmuştur.

Sonuç olarak bulgularımıza göre, adli yaş tahmini için müracaat eden kişiler daha çok kadındır. Yaş ortalaması 19,9'dur. Olguların önemli bir bölümünün doğum yerleri, kırsal bölgeler olup doğumları da sağlık kuruluşu dışında olduğu görüldü. Eğitim seviyeleri ise ilk-orta öğretim düzeyinde olan kalabalık aile çocuklarıdır. Kadınlar daha çok evlilik, erkekler ise iş başvurusu, askerlik gibi nedenlerle müracaat etmektedir. Adli makamlar doğumları sağlık kuruluşunda olan olgular için de (özellikle ceza hukuku nedenleri ile) adli yaşın belirlenmesini istemektedir. Nüfus kayıtlarında şüphe durumunda öncelikle doğum kayıtları esas aldığından, sağlık kuruluşlarında doğum kayıtları düzenli olarak arşivlenmelidir. Günümüzde doğumların tamamına yakını sağlık kuruluşunda olması, doğum kayıtlarının düzenli tutulmasına yönelik yasal düzenlemelerin olması nedeni ile yaşayan kişilerde adli yaş tahmini yapılan olgu sayısında azalma olabilir. Ancak, göç nedeni ile farklı bölge ya da ülkelerden gelen kişilerin varlığı nedeni ile yaşayan kişilerde yaş tahmini yapılmasının önemini korumaya devam edeceği öngörülmektedir. Farklı toplumlarda, çeşitli yaş gruplarında fiziksel gelişim bulgularının benzerlik göstermemesi nedeni ile adli yaş tahmini konusunda doktorlar dikkatli olmalı ve multidisipliner yaklaşımla adli-tıbbi değerlendirme yapılmalıdır.

Çıkar Çatışması ve Finans Durumu: Çalışmamız bir kurum ve kuruluşça finanse edilmemiştir. Bu çalışmada yazarlar arasında herhangi bir konuda çıkar çatışması bulunmamaktadir.

\section{KAYNAKLAR}

1. Baransel Isır A. Adli Hekimlikte Yaş Tayini. Sermet Koç, Muhammet Can. Birinci Basamakta Adli Tip. 2. Baskı, İstanbul Tabip Odas1, 2011;222-234

2. Payne-James J, Jones R, Karch SB, Manlove J. Identification of the Living and the Dead. Simpson's Forensic Medicine. 13th Edition. London: Hodder \& Stoughton Ltd; 2011. 35-41.

3. Demirkıran DS, Çelikel A, Zeren C, Arslan MM. Yaş Tespitinde Kullanılan Yöntemler. Dicle Tip Dergisi. 2014;41(1):238-243.

4. Schmeling A, Dettmeyer R, Rudolf E, Vieth V, Geserick G. Forensic Age Estimation. Dtsch Arztebl Int. 2016 Jan 29;113(4):4450 .

5. Schmeling A, Geserick G, Reisinger W, Olze A. Age Estimation. Forensic Science İnternational, 2007;165(2-3):178-181.

6. Yarımoğlu BH, Alper B, Meral D, Çekin N. Yaş Tayini Uygulamalarında Epifiz Plağı Kapanma Derecelerinin İncelenmesi. Adli Tip Bülteni. 2005;10(3):84-89.

7. Greulich W, Pyle SL. Radiographic Atlas of Skeletal Development of the Hand and Wrist. The American Journal of The Medical Sciences. 1959;238(3):393. 
8. Güler H, Kaya A, Meral O, Erdoğan N, Ertürk S. Investigation of Reasons For Age Assessment Demands Among Cases Who Appear to be in Children Age Bracket According To Their Birth Records: 6.5 Years Of Experience. Medicine Science.2015;4(4):2797-812.

9. Atılgan M, Akkoyun M. Akdeniz Üniversitesi Tip Fakültesi Adli Tip Anabilim Dalından Yaş Tayini İstenen Olguların Değerlendirilmesi. Adli Tip Bülteni. 2017;22(1):34-9.

10. Kaya K, Yıldırım KÇ, Çelik EB, Akgündüz E, Gülmen MK. Evaluation of Age Determination Cases. International Journal of Recent Scientific Research. 2018;9(7A):27774-27776.

11. Türkoğlu A, Tokdemir M, Sehlikoğlu K, Tunçez FT, Cavlak N, Börk T, ve ark.. Fırat Üniversitesi Tip Fakültesi Adli Tip Anabilim Dalına 2010-2015 Yılları Arasında Kemik Yaşı Tayini Nedeniyle Başvuran Olguların Değerlendirilmesi. Turkiye Klinikleri J Foren Med. 2016;13(1):1-7.

12. Hoşgör AG. Kadın Vatandaşlık Haklarındaki En Temel Sorun: "Nüfus Cüzdanım Yok Ki!". Toplum ve Demokrasi Dergisi. 2014;2(4):27-38.

13. T.C. Sağlık Bakanlığı Sağlık İstatistikleri Yıllığı 2017 Haber Bülteni. https://dosyamerkez.saglik.gov.tr/Eklenti/27344,saglik-istatistikleri-yilligi-2017-haber-bultenipdf.pdf?0. Erişim tarihi 20.12.2019.

14. Arslan MM, Çekin N, Akçan R, Saylak E. Hatay Ağır Ceza ve Asliye Hukuk Mahkemelerine 2007 Yılında Yansıyan Yaş Tespiti Davalarının İncelenmesi. Adli Tip Dergisi. 2008;22(2):8-13.

15. Aras B. Hukuk ve Ceza Mahkemelerinin Yaş Tespiti Kararlarının Birbirine Etkisi. Uyuşmazlık Mahkemesi Dergisi. 2015;(5):83112.

16. Baransel Isır A, Dülger HE. 1998-2005 Yılları Arasında Gaziantep Üniversitesi Adli Tıp Anabilim Dalında Raporlandırılan Yaş Tayini Olgularının Irdelenmesi. Turkiye Klinikleri J Foren Med. 2007;4(1):1-6.

17. Franklin D, Flavel A, Noble J, Swift L, Karkhanis S. Forensic Age Estimation in Living İndividuals: Methodological Considerations in The Context of Medico-Legal Practice. Research and Reports in Forensic Medical Science. 2015:5 53-66.

18. De Donno A, Santoro V, Lubelli S, Marrone M, Lozito P, Introna F. Age Assessment Using The Greulich and Pyle Method on a Heterogeneous Sample of 300 Italian Healthy and Pathologic Subjects. Forensic Science International. 2013;229(1-3):157. e1-. e6.

19. Altinsoy HB, Alatas O, Gurses MS, Inanir TN. Forensic Age Estimation in Living Individuals By 1.5 T Magnetic Resonance Imaging Of The Knee: A Retrospective MRI Study. Aust J Forensic Sci.2018; 1-15.

20. Santoro V, De Donno A, Marrone M, Campobasso CP, Introna F. Forensic Age Estimation of Living İndividuals: A Retrospective Analysis. Forensic Sci Int. 2009 Dec 15;193(1-3):129.e1-4.S 